\title{
The Level of Psychological Alienation and its Relationship to Some Demographic Variables among the Hearing - Impaired in Jordan
}

\author{
Naji Minwer Alsaaideh ${ }^{1, *}$ \\ ${ }^{1}$ Special Education, al - Balqa Applied University, Jordan \\ *Correspondence: Special Education, al - Balqa Applied University, Jordan.Tel.: \\ 962-77-2099-527. E-mail: najesaydeh@yahoo.com
}

Received: May 1, 2017 Accepted: May 23, 2017 Published: June 18, 2017

doi:10.5296/ije.v9i2.11149 URL: https://doi.org/10.5296/ije.v9i2.11149

\begin{abstract}
The study aimed at identifying the level of psychological alienation and its relationship with some demographic variables among the hearing- impaired in Jordan. The study sample consisted of (80) students from the Holy Land Institute for the Deaf allocated at (50) males and (30) females. The researcher developed a tool to measure the psychological alienation and verify the psychometric features of the tool.

The study results pointed out that the level of psychological alienation among the hearing impaired was at medium level. The results also revealed the absence of statistically significant differences in the level of psychological alienation between the hearing - impaired males and females. The study also showed the presence of statistically significant differences in the psychological alienation level according to the variables of type of residence and the intensity of impairment where the differences were in favor of the deaf students. Based on the results, the researcher recommends the necessity of holding training and guiding programs to reduce the level of psychological alienation among the hearing - impaired in Jordan.
\end{abstract}

Keywords: Psychological alienation, hearing - impaired, demographic variables 


\section{Introduction}

Psychological alienation received the attention of many researchers. Since studying this phenomenon is important for the public, its importance increases for people of special needs in general and the hearing - impaired in particular. Hearing - impaired individuals suffer rejection, alienation, doubt, fear, prejudice and bias.

Psychological alienation is of the clearest problems among the disabled and is characterized by the individual's feeling of alienation from themselves and their society. This makes them suffer many psychological and behavioral disorders in their lives (Daugherty \& Lintor, 2003:323).

As a result, the hearing - impaired prefer to stay home instead of going out and dealing with the society of hearers which leads them to feel inefficient in social transactions and the sense of depression and sadness. This enhances their feeling of social isolation where alienation and social rejection appear to be as an enhancement to the hearing - impaired individuals' view about themselves as a cultural or lingual minority (Bell \& Montarzino, 2006: 6).

Al - San'ani (2014) states that psychological alienation among hearing - impaired could result from the effects of the nature of the hearing impairment. The hearing - impaired are daily exposed to many situations that make them in need for the help and acceptance of others. They need people who are able to communicate with them, and this is what was pointed out by brown (2000) in that the relationship between alienation and the need for communication with others is direct, i.e the more the need for communication was, the more was the feeling of alienation.

Moschella (1992) indicates that the hearing - impaired are more liable to alienation, isolation, chyness, shame, unwillingness and depression than others. Abul - Su'oud (2004) points out that self - liquefaction and loss of identity increase among the hearing - impaired who show the symptoms which accompany alienation such as the feeling of unsuitableness, life meaninglessness, powerlessness and rebellion leading to lack of self - adaptation and self unconformity. Rejection and negligence do not necessarily lead to isolation or psychological loneliness as the hearing - impaired may suffer alienation to a certain degree that could make them neglect or refuse their willingness to maintain their social relationships with their peers (Elhageen, 2004:37).

The researcher argues that the hearing - impaired suffer the tough and complicated life circumstances because of the absence of communication language with hearers which leads to isolation, aversion from others, anxiety, indifference and psychological alienation. It could be said that the feeling of psychological alienation is the starting point for many problems and disorders suffered by the hearing impaired. This study has come to shed light on (psychological alienation among the hearing impaired people) as a new addition to the studies which discuss alienation, especially among individuals with special needs particularly the hearing impaired category in the Jordanian Society.

Many researchers tackled psychological alienation and its relationship with some variables. The study of (Brown, 2000) aimed at identifying the levels of alienation and the 
corresponding levels of communication need with others. The study sample consisted of (1739) students. The researcher stated that the relation between alienation and the need for communication with others was direct, i.e the more was the need for communication the more increased was the feeling of alienation.

The study of (Elhageen, 2004) aimed at identifying the interaction between the parental methods of treatment and the relation with peers in the classroom and its effect on psychological loneliness among deaf children in Egypt. The study sample consisted of (387) deaf children. The study results revealed the absence of statistically significant differences in the means of psychological loneliness degrees among the male and female deaf children while there were statistically significant differences in the means of psychological loneliness degrees between the deaf and hearing children where the differences were in favor of the hearing children.

Abul - Su'oud (2004) conducted a study which aimed at recognizing the effectiveness of a heuristic program in reducing the alienation level among hearing - impaired adolescents in Egypt. The study sample consisted of (40) hearing - impaired male and female adolescent students. The sample was divided into two groups: An experimental group of (20) male and female students and a control group of (20) male and female students. The study results pointed out the dip of alienation level among the experimental group's members after applying the program. The results also showed the non - existence of statistically significant differences due to gender variable among the experimental group's members on post measurement.

In the study of Al - San'ani (2009) to identify the relationship between psychological alienation and parental treatment methods among the hearing - impaired students according to the variables of: Governorate, gender, age when losing hearing and type of hearing disability; the study sample consisted of (126) students: (71) males and (55) females. The results showed that the hearing - impaired individuals do not suffer psychological alienation, with the presence of statistically significant differences in psychological alienation among the hearing - impaired students pursuant to the governorate variable while such differences did not exist in the variables of (age when losing hearing, gender, type of hearing disability). The study also showed the absence of interaction in the psychological alienation according to the previously mentioned variables.

The study of Saleh (2014) aimed at identifying the level of psychological alienation among the hearing - impaired adolescents at the center of young deaf and mute in M'sila province in Algeria, and also to realize if there are any differences in psychological alienation according to the variables of (gender, impairment severity, accommodation style, residential area, nature of impairment). The study sample consisted of (50) hearing - impaired individuals whose ages ranged between $(12-18)$ years. The results indicated that the level of psychological alienation among the hearing - impaired adolescents was medium, the study results also revealed the absence of statistically significant differences in psychological alienation among the hearing - impaired students due to the variables of impairment severity, accommodation style and residential area while there were statistically significant differences due to the 
variables of gender in favor of the males and the nature of impairment in favor of the genetically impaired.

The study of Nawfal (2016) aimed at studying the body image and psychological alienation and its relationship with anxiety and depression and their relationship with some demographic variables: (gender, age, impairment degree, impairment causes) among the impaired. The study sample consisted of (155) impaired persons: (80) males and (75) females. The study results revealed a statistically significant correlation between psychological alienation and anxiety and depression. The results also pointed out the absence of statistically significant differences in the psychological alienation level due to the variable of impairment degree, also for gender except for the isolation dimension which was in favor of the females.

\section{Method and Procedures}

\subsection{Questions of the Study}

The following are sub - questions that are derived from the main one above:

1. What is the level of psychological alienation among the herring - impaired in Jordan?

2. Are there statistically significant differences in the level of psychological alienation at $(a=0.05)$ among the herring - impaired in Jordan pursuant to the variables: type of impairment, residential area and gender?

\subsection{Objectives of the Study}

The study aims at achieving the following:

1. Identifying the level of psychological alienation among deaf students in Jordan.

2. Identifying the difference of psychological alienation level among the-Hard Hearing students in Jordan due to the difference in the type of impairment, residential area and gender.

\subsection{Terms Used in the Study}

\subsubsection{The Psychological Alienation Tool}

The researcher developed the tool of psychological alienation by referring to the theoretical literature and the previous studies in psychological alienation, Al - San'ani (2009), Abul Sa'oud scale (2004), Mahiub scale (2002) and zahran scale (2002). The tool in its final form consisted of (36) clauses distributed on (4) dimensions: social Isolation (9) clauses, powerlessness (9) clauses, Meaninglessness (8) clauses and Rebellion (10) clauses.

\subsubsection{Validity of Internal Consistency}

In order to extract the internal consistency validity of the scale, the correlation coefficients of the scale clauses were extracted together with the dimension and the total score in an exploratory sample from outside the study sample consisted of (30) male and female hearing 
- impaired students, whereby the scale clauses were analyzed and the correlation coefficients were calculated between each clause and its correlation to the dimension to which it belongs, and between each clause and the total score. The correlation coefficients of the clauses with the tool as a whole ranged between $(.46-.86)$ and with the dimension $(.44-.89)$. table (2) shows the results.

Table 2. The Correlation Coefficients between the Clauses and the Dimension and the Total Score of the Tool

\begin{tabular}{ccccccccc}
\hline $\begin{array}{c}\text { Item } \\
\text { No. }\end{array}$ & $\begin{array}{c}\text { Correlation } \\
\text { coefficient } \\
\text { dimension }\end{array}$ & $\begin{array}{c}\text { Correlation } \\
\text { coefficient } \\
\text { with tool }\end{array}$ & $\begin{array}{c}\text { Item } \\
\text { No. }\end{array}$ & $\begin{array}{c}\text { Correlation } \\
\text { coefficient } \\
\text { dimension }\end{array}$ & $\begin{array}{c}\text { Correlation } \\
\text { coefficient } \\
\text { with tool }\end{array}$ & $\begin{array}{c}\text { Item } \\
\text { No. }\end{array}$ & $\begin{array}{c}\text { Correlation } \\
\text { coefficient } \\
\text { dimension }\end{array}$ & $\begin{array}{c}\text { Correlation } \\
\text { coefficient } \\
\text { with tool }\end{array}$ \\
\hline 1 & $* * .76$ & $* * .86$ & 13 & $* * .68$ & $* * .62$ & 25 & $* * .63$ & $* .47$ \\
2 & $* .44$ & $* .46$ & 14 & $* * 72$ & $* * .61$ & 26 & $* * 75$ & $* * .64$ \\
3 & $* 47$ & $* .67$ & 15 & $* * .63$ & $* * .63$ & 27 & $* .49$ & $* * .67$ \\
4 & $* * .59$ & $* * .59$ & 16 & $* * .75$ & $* * .75$ & 28 & $* * .67$ & $* .55$ \\
5 & $* * .62$ & $* * .54$ & 17 & $* * .71$ & $* * .77$ & 29 & $* * .71$ & $* * .59$ \\
6 & $* * .62$ & $* * .58$ & 18 & $* * .61$ & $* .46$ & 30 & $* .49$ & $* * .66$ \\
7 & $* * .85$ & $* * .53$ & 19 & $* * .72$ & $* * .58$ & 31 & $* * .89$ & $* * .60$ \\
8 & $* .47$ & $* * .58$ & 20 & $* * .63$ & $* * .78$ & 32 & $* * .73$ & $* * .67$ \\
9 & $* * .67$ & $* * .52$ & 21 & $* * .69$ & $* * .56$ & 33 & $* * .68$ & $* .51$ \\
10 & $* * .76$ & $* * .76$ & 22 & $* * 63$ & $* * .65$ & 34 & $* * .68$ & $* .46$ \\
11 & $* * .76$ & $* * .75$ & 23 & $* * .65$ & $* * .62$ & 35 & $* * .69$ & $* .47$ \\
12 & $* * .76$ & $* * .68$ & 24 & $* * .69$ & $* * .67$ & 36 & $* * .61$ & $* .48$ \\
\hline
\end{tabular}

\subsubsection{Reliability of the Tool}

The researcher verified the reliability of the scale by applying it on an exploratory sample outside the study sample consisted of (30) male and female hearing - impaired students through calculating the internal consistency coefficient by using Cronbach's Alpha equation which reached at (.89) for the scale in general, and ranged between $(.78-.91)$ in its four dimension. This indicates the existence of scale reliability which is adequate for the purposes of the study. Table (3) shows the internal consistency coefficient by using cronbach alpha for the scale in general and for the four dimensions.

Table 3. Cronbach Alpha Coefficients for Each Dimension of the Tool and for the Tool as a Whole

\begin{tabular}{cccccc}
\hline $\begin{array}{c}\text { Tool } \\
\text { dimensions }\end{array}$ & Isolation & Rebellion & Powerlessness & Meaninglessness & $\begin{array}{c}\text { Total } \\
\text { score }\end{array}$ \\
\hline $\begin{array}{c}\text { Cronbach } \\
\text { alpha } \\
\text { coefficient }\end{array}$ & 0.78 & 0.83 & 0.91 & 0.81 & 0.89 \\
\hline
\end{tabular}




\section{Macrothink}

\subsection{Limitations of the Study}

1. Temporal limit: Second semester of the academic year 2015 / 2016.

2. Spatial limit: Holy Land Institution for the deaf.

3. Human limit: Hearing impaired students.

\subsection{Population and Sample of the Study}

The study population consisted of the deaf students in the Holy Land Institution for the deaf in Jordan, who counted (120) male and female students according to the statistics of centers. The study sample contained (80) male and female hearing - impaired students who were selected through the simple random method. Table (1) shows the frequencies and percentages of the sample according to the variables of impairment severity, gender and residential area.

Table 4. Frequencies and Percentages According to the Variables of Impairment Severity, Gender and Residential Area

\begin{tabular}{cccc}
\hline Variables & Categories & Frequency & Percentage\% \\
\hline Type of & Deafness & 50 & 56.2 \\
impairment & Hard Hearing & 30 & 43.8 \\
Gender & Male & 50 & 56.2 \\
& Female & 30 & 43.8 \\
Residential & Permanent & 55 & 65.75 \\
area & Diurnal & 25 & 31.25 \\
& & 80 & 100.0 \\
\hline
\end{tabular}

\subsection{Research Instrument}

The researcher developed a questionnaire for the purpose of the current study to measure the degree of psychological alienation among the Hard Hearing in Jordan.

\subsection{Statistical Treatment}

To answer the study questions, the use of statistical treatments were as follows: Arithmetic means and standard deviation. and $\mathrm{T}$ - Test and cronbach alpha.

\subsection{Statistical Standard}

To explain the arithmetic averages of the estimates of a sample of graduate students in the statistical follows:

From $1-2.66 \quad$ low degree

From $1.67-2.37 \quad$ Medium degree

From $2.38-3$ High degree 


\section{Results and Discussion of the Study}

3.1 Results and Discussion of the first question which is: "What is the level of psychological alienation among deaf students in Balqa governorate in Jordan? To answer this question, the arithmetic means and standard deviations were extracted for the difference in the level of psychological alienation among the hearing - impaired students. Table (4) shows the results.

Table 4. The Arithmetic Means and Standard Deviations for the Psychological Alienation Scale Dimensions

\begin{tabular}{cccccc}
\hline No. & Dimension & Mean & $\begin{array}{c}\text { Standard } \\
\text { deviation }\end{array}$ & Sequence & Degree \\
\hline 1 & Social isolation & 2.11 & 0.29 & 1 & Medium \\
2 & Rebellion & 1.90 & 0.39 & 2 & Medium \\
3 & Powerlessness & 1.83 & 0.44 & 3 & Medium \\
4 & Meaninglessness & 1.82 & 0.44 & 4 & Medium \\
& Total score & 1.92 & 0.31 & --- & Medium \\
\hline
\end{tabular}

The results of table (4) indicate that the level of total psychological alienation was average where the total arithmetic mean was (1.92). The researcher attributes this result to the fact that the hearing - impaired learn in a special institution and that they interact with their families and others using a special language that facilitates their interaction and avoid them the need for creating interactions with hearing individuals. Consequently, their interaction chances with hearers are very limited because the sign language is not spread among hearers which may make them feel alienated in their surroundings. The result of the present study agreed with the results of the study of Saleh (2014) which indicated that the level of psychological alienation among the hearing - impaired was average and the study of (Brown, 2000) which pointed out that the relation was direct between alienation and the need to communicate with others i.e, the more increased the need for communication was, the more increased was the feeling of alienation. The results of the present study contradicted the study of Al - San'ani (2009) which revealed that hearing - impaired individuals do not suffer psychological alienation.

3.2 Results and discussions of the second question which is: "Are there statistically significant differences in the level of psychological alienation at $(a=0.05)$ among the hearing - impaired in Jordan according to the variables of: type of disability, residential area and gender?

3.2.1 Results related to gender: To identify the level of psychological alienation among the hearing - impaired students pursuant to gender, the arithmetic means, standard deviations and $\mathrm{T}-$ test were extracted for deaf students. Table No. (5) shows the results. 
Table 5. $\mathrm{T}$ - Test Results for the Differences Significance between the Males and Females Means Concerning Psychological Alienation

\begin{tabular}{ccccccc}
\hline Dimension & Gender & means & $\begin{array}{c}\text { Standard } \\
\text { deviation }\end{array}$ & $\begin{array}{c}\text { T }- \\
\text { value }\end{array}$ & d.f & Sig. \\
\hline \multirow{2}{*}{ Social isolation } & Males & 2.11 & 0.31 & 0.176 & 99 & 0.861 \\
& Females & 2.10 & 0.23 & & & \\
Rebellion & Males & 1.87 & 0.39 & 1.868 & 99 & 0.065 \\
& Females & 2.04 & 0.40 & & & \\
Powerlessness & Males & 1.82 & 0.42 & 0.119 & 99 & 0.906 \\
& Females & 1.84 & 0.49 & & & \\
Meaninglessness & Males & 1.82 & 0.42 & 0.119 & 99 & 0.906 \\
& Females & 1.84 & 0.49 & & & \\
Total score & Males & 1.91 & 0.31 & 0.345 & 99 & 0.731 \\
& Females & 1.94 & 0.33 & & & \\
\hline
\end{tabular}

Table (5) shows the absence of statically significant differences at $(a=0.05)$ in the level of psychological alienation according to gender difference in the total score of the scale and its four dimensions. The researcher attributes this to that hearing impairment has approximate effects on males and females as it imposes obvious constraints on the individual - male or female - most prominently the shortcoming in communication skills. This result agreed with the study of Abul - So'ud (2004) and the study of (Elhageen, 2004) which indicated the non existence of statistically significant differences in psychological alienation among the hearing - impaired students due to the variable of gender. Yet, the present study contradicted with the study of Saleh (2014) which pointed out the presence of statistically significant differences in psychological alienation among the hearing - impaired students due to gender in favor of males.

3.2.2 Results related to the impairment severity: To identify the differences in the level of impairment severity among the hearing - impaired students, the arithmetic means, standard deviations and $\quad \mathrm{T}-$ test were arranged.

Table (6) shows statistically significant differences at $(a=0.05)$ in the level of psychological alienation on the total score in favor of the deaf especially in the social isolation and rebellion according to the type of Hard Hearing. However, the results did not show statistically significant differences at $(\mathrm{a}=0.05)$ in the level of psychological alienation in the dimensions of powerlessenss and meaninglessness of life due to the difference of the type of Hard Hearing. The researcher attributes the differences in the level of psychological alienation on the total score especially on the social isolation and rebellion for the difference in the type of Hard Hearing in favor of the deaf to the isolation of the deaf students from society because of their existence in a boarding center where they interact through a special language for the deaf, their tendency to withdrawl from the social activities of the hearing people, their feeling of the infeasibility of those activities, their lack of social links with hearers and their feeling of loneliness and isolation, and this is what was pointed out by (Bell \& Montarzino, 2006) 
who stated that the Hard Hearing prefer staying home to going out and dealing with the hearing people society which makes them feel inactive in social interactions which enhances their sense of social isolation. The feeling of inferiority and alienation generates hatred and anger toward all the surrounding social values, standards and controls. They are unsatisfied with themselves and their society. They tend to challenge laws and regulations and rebel against them. The results of the current study also indicate the absence of differences in the level of psychological alienation on the powerlessness and meaninglessness dimensions due to the differences in the type of Hard Hearing, and the researcher attributes this result to the fact that hearing impairment imposes many communicative, social, educational or emotional problem among the hearing - impaired because the deaf or impaired person are both enlisted under what is called hearing impairment and consequently the deaf person is encountered by an inferior look and negative attitudes which make them feel that they are living a meaningless and purposeless life and that they are unable to realize their goals and ambitions. This is the reason for not having differences among them concerning psychological alienation. The results of the present study agreed with those of (Elhageen, 2004) which revealed statistically significant differences in the feeling of psychological loneliness between the deaf and hearing children where the differences were in favor of the deaf children. The results of the present study contradicted the results of Saleh (2014) and Al - San'ani (2009) the results of which showed the non - existence of statistically significant differences in the psychological alienation among the Hard Hearing students due to the variable of Hard Hearing severity.

Table 6. Results of $\mathrm{T}$ - Test for the Differences Significance in the Level of Psychological Alienation According to the Type of Impairment

\begin{tabular}{|c|c|c|c|c|c|c|}
\hline Dimension & $\begin{array}{c}\text { Type of } \\
\text { impairment }\end{array}$ & Mean & $\begin{array}{l}\text { Standard } \\
\text { deviation }\end{array}$ & $\begin{array}{c}\mathrm{T}- \\
\text { value }\end{array}$ & d.f & Sig. \\
\hline \multirow{3}{*}{ Social isolation } & Hard & & & \multirow{3}{*}{3.234} & \multirow{3}{*}{99} & \multirow{3}{*}{$* 0.002$} \\
\hline & Hearing & 2.03 & 0.31 & & & \\
\hline & Deafness & 2.21 & 0.23 & & & \\
\hline \multirow{3}{*}{ Rebellion } & Hard & 1.83 & 0.30 & \multirow{3}{*}{2.283} & \multirow{3}{*}{99} & \multirow{3}{*}{$* 0.025$} \\
\hline & Hearing & 1.05 & 0.30 & & & \\
\hline & Deafness & 2.00 & 0.47 & & & \\
\hline \multirow{3}{*}{ Powerlessness } & Hard & 1.79 & 0.34 & \multirow{3}{*}{0.997} & \multirow{3}{*}{99} & \multirow{3}{*}{0.321} \\
\hline & Hearing & & & & & \\
\hline & Deafness & 1.88 & 0.53 & & & \\
\hline \multirow[t]{2}{*}{ Meaninglessness } & $\begin{array}{c}\text { Hard } \\
\text { Hearing }\end{array}$ & 1.79 & 0.34 & \multirow[t]{2}{*}{0.997} & \multirow[t]{2}{*}{99} & \multirow[t]{2}{*}{0.321} \\
\hline & Deafness & 1.88 & 0.53 & & & \\
\hline \multirow[t]{2}{*}{ Total score } & $\begin{array}{c}\text { Hard } \\
\text { Hearing }\end{array}$ & 1.86 & 0.26 & \multirow[t]{2}{*}{0.045} & \multirow[t]{2}{*}{99} & \multirow[t]{2}{*}{$* 0.044$} \\
\hline & Deafness & 1.99 & 0.36 & & & \\
\hline
\end{tabular}

* The differences are statistically significant at $(\mathrm{a}=0.05)$ 
3.2.3 The results related to the variable of residential area: To identify the difference in the level of psychological alienation among the Hard Hearing students in Balqa governorate in Jordan pursuant to the residential area variable, the arithmetic means, standard deviations and $\mathrm{T}$ - test were extracted to the Hard Hearing students responses. Table (7) shows the results.

Table 7. The Results of T - Test to the Differences Significance in the Level of Psychological Alienation Pursuant to the Variable of Residential Area

\begin{tabular}{ccccccc}
\hline Dimension & $\begin{array}{c}\text { Residential } \\
\text { area }\end{array}$ & Mean & $\begin{array}{c}\text { Standard } \\
\text { deviation }\end{array}$ & $\begin{array}{c}\text { T }- \\
\text { value }\end{array}$ & d.f & Sig. \\
\hline \multirow{2}{*}{ Social isolation } & Permanent & 2.17 & 0.20 & 1.555 & 99 & 0.123 \\
& Diurnal & 2.08 & 0.33 & & & \\
Rebellion & Permanent & 2.09 & 0.48 & 3.751 & 99 & $* 0.000$ \\
& Diurnal & 1.80 & 0.29 & & & \\
Powerlessness & Permanent & 1.97 & 0.56 & \multirow{2}{*}{2.483} & 99 & $* 0.015$ \\
& Diurnal & 1.75 & 0.33 & & \\
Meaninglessness & Permanent & 1.97 & 0.56 & \multirow{2}{*}{2.483} & 99 & $* 0.015$ \\
& Diurnal & 1.75 & 0.33 & & & $* 0.003$ \\
\hline
\end{tabular}

* The differences are statistically significant at $(\mathrm{a}=0.05)$

The results shown in table (11) point out the presence of statistically significant differences in the level of psychological alienation at the total score and three dimensions which are (rebellion, powerlessness, meaninglessness) due to the difference of the residential area and the differences were in favor of the permanent residence individuals. The results did not indicate the existence of statistically significant differences in the level of psychological alienation in the social isolation dimension due to the residential area variable. The researcher attributes this result which refers to the presence of statistically significant differences in the level of psychological alienation on the total score and the dimensions of rebellion, powerlessness and meaninglessness due to the variable of residential area to the hearing impaired individual's feeling of the lack of positivity and efficiency, their disability to be independent in their life affairs, their inability to hold responsibility and make decisions in life problems and their dependence on others. This may be reflected as mush meaning as the impairment in the psych of the hearing impaired person. The hearing impaired person believes that life is meaningless and that he / she cannot control events. This makes them feel rejection, hatred and anger and rebellion against the surroundings and feels inclined to challenge authorities and disrespect to customs and traditions. The researcher attributes the non - existence of statistically significant differences in the level of psychological alienation on the dimension of social isolation according to the difference of residential area variable to the fact that the hearing - impaired - The deaf and hearing disability - live in a silent and 
unknown world wrapped with owe and fear from the surrounding dangers whether at home, the street or the center. The absence of communication means with the hearing society and the lack of interaction with society make them feel lonely, isolated and alienated. The results of the current study agree with the study of Saleh (2014) which stated the absence of statistically significant differences in the level of psychological alienation among the hearing - impaired students due to the residential area variable. The results of the present study contradicted with those of the studies of Saleh (2014) and Al - San'ani (2009) which indicated the non - existence of statistically significant differences in psychological alienation among the hearing - impaired students due to the residential area variable.

\section{Recommendation}

- Preparing training and directive programs to reduce the level of psychological alienation among the hearing - impaired in Jordan.

- Merging the hearing - impaired category at the public education institutions and societal activities to perform successful social interactions with the hearing society.

- Improving the level of life - quality for the hearing - impaired through providing them with qualitative services and job opportunities to make them feel as effective and productive members in society not just dependent individuals.

\section{References}

Abul - Su'oud, Shadi (2004). The effectiveness of a directive program in reducing the level of psychological alienation among hearing - impaired adolescents. unpublished M.A. Faculty of Ein Shams University, Egypt.

Al-San'ani, Abdo. (2009). The relationship between psychological alienation and parental treatment styles among the hearing - impaired students at the secondary stage, unpublished M.A, faculfy of Education Taa'z university, Yemen.

Bell, S., \& Montarzino, A. (2006). Open space Research Centre. Access to the countryside by deaf visitors. Scottish Natural Heritage Commissioned Report No. 171. (ROAME No. F03AB05).

Brown. R. (2000). School connection and alienation. university of Nevada, U.S.A.

Daugherty, T. K., \& Lintor, J. M. (2003). Assessment of Social Alienation: Psychometric Properties of the Sacs-R. Social Behavior \& Personality, 28(4), 320-334.

Elhageen, Adel Abdelfatah M. (2004). Effect of Interact on between Parental Treatment Styles and Peer Relations in Classroom on the Feelings of Loneliness among Deaf Children in Egyptian Schools, PH.D, Faculty of Education and Social Science, EberhardKarls University Tubingen, Germany, http://deposit.ddb.de/cgi-(2016:20/07). 


\section{Macrothink}

Mahyoub, Suheir (2002). psychological and social alienation and its relationship with radicalism toward violence among the youth resided in touristic areas. Journal of contemporary education, 1(62), 195-215.

Moschella, J. (1992). The Experience of Growing up Deaf or hard of hearing Implications of Sign Language Versus Oral Rearing on Identity Development and Emotional well Being. Dissertation Abstract International, 53(11B), 5989.

Nawfal, Nasser. (2016). Body image and psychological alienation and its relationship with anxiety and depression among vision - impaired, unpublished M.A, faculty of Education, Islamic University, Gaza.

Saleh, Yamineh. (2014). Psychological alienation among persons with special needs, field study, hearing impaired adolescents at the young deaf center in the state of Al-Masilah, unpublished M.A, faculty of human and social sciences, Mohammad Budiaf university, Algeria.

Zahran, Sanaa. (2002). The effectiveness of a rational emotional directive program to correct the alienation beliefs of university students, unpublish Ph.D dissertation, Dumiat Faculty of Education, Al-Mansourah university.

\section{Copyright Disclaimer}

Copyright for this article is retained by the author(s), with first publication rights granted to the journal.

This is an open-access article distributed under the terms and conditions of the Creative Commons Attribution license (http://creativecommons.org/licenses/by/3.0/). 